\title{
The Characteristics and Methods of Autonomous Learning of Higher Mathematics
}

\author{
Yu Zhifeng ${ }^{1, \text { a }}$ \\ ${ }^{1}$ Nanchang Institute of Science and Technology, Nanchang 330108, China \\ ayuzhifeng@126.com
}

Keywords: Higher mathematics, Teaching ability training, Learning ability

\begin{abstract}
. higher vocational education personnel training is able to meet the needs of the first line of the production of high-tech group of comprehensive talents. In order to cultivate students into innovative talents, we must attach importance to the cultivation of students' autonomous learning ability. Combining with the teaching practice of Higher Mathematics for many years, the author makes some discussions on the cultivation of students' autonomous learning ability.
\end{abstract}

\section{Introduction}

The Ministry of education No. 16 made it clear that the training goal of higher vocational education is highly skilled and practical talents. Vocational education is not only to teach students how to do things, more important is to teach students how to behave. On June 18, 1997, Vice Premier Li Lanqing of Shenzhen Polytechnic wrote "and the higher occupation technique education, cultivating excellent talents with noble occupation morality and skilled occupation skills". Li Lanqing's inscription for us to accurately establish vocational training target direction is pointed out. On the basis of the educational goal, quality in business, vocational education and training of personnel, and is not fixed in a post operation type "craftsmen", but has the ability of autonomous learning, learning to adapt to the production of the first line of high-tech talents need comprehensive post group. Higher mathematics curriculum is an important part of cultivating students' learning ability. In the years of teaching practice, the author has made the following attempts to develop students' autonomous learning ability.

\section{The Importance of Students' Autonomous Learning}

Students' autonomous learning ability has a direct impact on their learning effectiveness. Clear the autonomous learning ability of the connotation, structure and dynamic process in the learning activities, will help to improve the ability of autonomous learning, to help students achieve success in learning and life, it has practical significance for the sustainable development with the development of the times, to cultivate talents. Self regulated learning, also known as self regulated learning, generally refers to the process of determining the learning goal, choosing the learning method, monitoring the learning process and evaluating the learning result. Learner autonomy is the main body of learning, which reflects the value orientation of modern education and curriculum. According to the characteristics of learner autonomy and the dynamic structure in different age stages, autonomous learning has broad sense and narrow sense. Generalized autonomous learning refers to the growth of knowledge, skill, talent, or development of a person at any time and in any environment by any means, with the help of his own efforts. The narrow sense refers to the students autonomous learning, autonomous learning, development and change their mind based on the students, with the help of peer and teacher's help, according to the actual situation and the society, the school education offered their requirements, objectives and tasks for their own learning, consciously plan, regulation, control and evaluation the learning process.

In the process of autonomous learning, students through experience, practice, gained some experience and lessons, they may have taken some detours, but eventually learned to learn, improve the awareness and ability to innovate. For example, children in rural areas in the north, after a long 
winter sports activities such as snowball fights, throwing ability has been greatly improved, teachers may find the students throwing methods are different, not all children are using the so-called "behind the shoulders" method of throwing, and many students do not use approach and direct object throwing out and throwing motion similar to the "left", mainly by the forearm and wrist force out from the side of the body. This is not consistent with the traditional method of throwing sports teaching of throwing technology requirements, but in practice the students to obtain the most effective method so that the teacher did not throw, what needs to be done to correct the mistakes, but the master in students throwing methods, inspire students to use better and more widely. If the student can use this method to come up with such as throwing "through the circle" and "dashuipiao" and "anti-aircraft missiles" such action, that a student has been greatly improved in the innovation ability and application ability, this is what we expect the new physical education curriculum.

The most important thing is that the students are able to adjust their learning state constantly, make use of their own knowledge, ability and the resources available to carry out effective learning. The students are the knowledge foundation of individuals, their studies are carried out on the basis, especially their cognitive knowledge, can help them learn more effectively, adjusting strategies in motivation, is constantly learning significance and value, to enhance their power source, has become an important support for learning the. Summary, autonomous learning is that learners make use of existing knowledge and cognitive level, to determine learning goals, choose learning methods, monitor learning process and evaluate learning results and other aspects of self design, self management, self adjustment, self control, self judgment, self evaluation and self transformation initiative is a learning process. Positive psychological reaction on learners' learning behavior and the formation of. It is based on the essence and definition of "autonomous learning". Self-conscious consciousness is a kind of personality tendency, and it is a kind of human behavior. Independent learning is different from dependent learning, autonomous learning requires students to have a sense of awareness and reaction to their own learning, learning, learning, how to learn, and so on.

\section{The main body of autonomous learning is of course students.}

In the traditional classroom, the students are only the tools for the teachers to carry out the teaching plan and accomplish the teaching tasks. The learning behavior of the students is passive, and no matter how the teacher's teaching level, the students can't change the way of teaching. The classroom teaching with the health curriculum can reflect the autonomous learning mode in many aspects Content, the choice of learning methods, the right to choose the progress of learning, which are around the main body to consider, therefore, students in the classroom, we can feel the position of the master, feel the power and freedom.

At the same time, the role and the role of the teacher are determined. In the traditional sports teaching, we have been used to sing the protagonist, has been accustomed to a way of teaching indoctrination. At the same time, as a way of promoting students' autonomous learning, teachers will become the designers of the classroom teaching process, the guidance and help of the students, but not the bystanders outside the classroom study. It should be said that teachers in the process of students' autonomous learning in the process of more weight, higher requirements, teachers' teaching more humane. Autonomous learning is a broad space for teachers to provide students with a relatively loose time, allowing students to achieve their learning goals through their own choices and practices. Therefore, each student in such a learning environment is an independent body of learning, you can use their own way of thinking, to analyze the possibility of reaching the goal, and to be confirmed in practice. Teachers should encourage students to adopt this kind of independent learning style, because it helps students to improve their abilities. When students encounter difficulties, teachers should give students appropriate help and support, but do not use a direct approach that is simple, but should use the inspiration, guidance and other means to help students improve their awareness and ability to solve problems independently, enhance students' self-confidence, so that they can eventually through continuous practice, improve learning methods and reach the goal of study. 


\section{Independent learning is very important.}

In a physical education class, teachers give students a learning goal: to develop the ability to bounce. For the learning objectives, teachers is explained: the development of spring, the first to know the status of bounce, the easiest way is to measure in jump high scores, after a period of training, the scores have improved significantly, it improves the bounce force. So the students are very happy to carry out the vertical jump to touch the high performance test. The next step is to use what method and how much time to improve their bounce. The teacher gave the students two weeks time, in what way by the students themselves, this class also requires students to use their own methods of practice, teachers can provide students with advice. The teacher told us, the development of spring is not a short duration of time things, and there are many methods, everyone can often change the practice method, the purpose of doing so is to maintain the freshness, the two is the method between can be mutually complementary role adjustment. In addition, teachers also require students to persevere, practice every day, but not excessive.

\section{Effective Method}

In the Course of Teaching Carefully Designed to Guide Students to Carry out Independent Learning. In the classroom teaching, we should give full play to the main role of the students and let the students participate in the teaching work. Before class targeted assignments to guide students through the Internet and other ways to collect relevant formulas that background and mathematics classroom teachers taught by anecdote; and inspired a combination of teaching methods of mathematical theory, solving methods to explain, explain your fine not more expensive, you can set aside the suspense, pay attention to lead thinking, learning direction for students next; the students will be divided into several groups according to the essence and content of teachers' learning, textbook chapters or a textbook outside the counseling book let the students read, and prepare some with analysis and answer math problems to the students; to create opportunities for students to express, in a semester, all the best students have the opportunity in the classroom for solving methods, for students to learn new topic to explain.

In Classroom Teaching, We Should Pay Attention to Encourage and Guide Students' Independent Thinking Mode. Innovation consciousness and ability lies in the development of thinking ability, only to think, there will be innovation, there will be results. Therefore, mathematics teaching is not only to make students form a unified, fixed, efficient computing methods and skilled computing skills, but also to cultivate students' thinking ability. In mathematics teaching, teachers should encourage students and respect the diversity of independent thinking, so that all students can actively participate in the discussion, let students dare to think, dare to think, say, in the process of thinking and speaking, stimulate students' thinking, and pay attention to the thinking method of teachers show students, an important tool for real let mathematics become rational communication and thinking about problems.

To Strengthen the Relationship between Mathematics Teaching and Reality and Arouse Students' Interest in Learning. There is a low interest in mathematics learning of vocational college students, which is not related to the abstract of mathematical concepts and the practicability of mathematics. Students in the study of mathematics generally feel mechanical, tasteless, boring, this is a long time since the mathematical education from the students rely on the survival of the real world, learning mathematics for mathematics. Therefore, teachers should try to tap the realistic background make students interested in mathematics concept, fully carry out the life and practice of mathematics in mathematics teaching thought, teaching by students to solve practical problems often encountered in daily life. As for the arrangement of the football league learning permutation and combination of knowledge, statistical thinking on permeability optimization problem to buy tickets in the search for mathematical problems in mobile phone packages, let the students look at the real life from the view of mathematics, combined with the actual life of learning mathematics.

Guide Students to Make Full Use of Network Multimedia Information Technology Learning. In teaching, guide students to use the multimedia information technology learning, can not only help 
students improve their ability to acquire skills and experience, to help students improve their ability of thinking and understanding, but also can cultivate students' autonomous learning ability and good learning habits. We will come up with some important theorems and concepts in the textbooks of higher mathematics. If 1 hospitcl rule, "Rolle theorem" and "Taylor formula" and so on. The study of these theorems and concepts is important not only for the study of advanced mathematics, but also for the improvement of the quality of mathematics. Most of these theorems and concepts are named after important mathematical figures. The teachers to guide the students in the classroom teaching in the process of using the network to understand the pioneers of life and work, we can not only complete the teaching task in the limited time also can improve the students' interest in learning, mathematics education thought.

\section{Pay Attention to the Guidance of Learning Methods, Improve Students' Learning Ability.}

Teaching and learning is a bilateral activity, we should start from the two aspects of improving teachers' teaching ability and students' learning ability. Teachers can give students introduce their own learning experience, tell them how to understand the mind of how to prepare formula, find the problem, how to take notes of the lectures, how to review and summarize the static knowledge from books into vivid knowledge in the students' mind. Some of the poor learning ability of students, according to their characteristics, specially formulated under the class review plan for them, very specific guidance to how they review, gradually establish their self-confidence, change the fear of mathematics learning psychology, improve the learning interest in mathematics, cultivate a correct learning habits, establish a good the foundation for follow-up study.

Set up Mathematical Modeling Elective Courses for Mathematical Modeling Training and Competition. In higher mathematics, many of the introduction of the concept using the ideas and methods of mathematical modeling, for example, starting from the concept of derivative and curve tangent slope of the instantaneous velocity rectilinear motion of the ladder from the area of irregular curved edge of introducing the concept of the definite integral. In the course of teaching, teachers should introduce some simple models, which can not only enrich the content of college mathematics, but also activate the classroom atmosphere. Not only the teaching of the classroom is permeated with the idea of mathematical modeling, but also the training of mathematical modeling and the organization of the college level competition and the participation in the National Mathematical Modeling contest. The students participated in the activities of mathematical modeling can basically through the collection, collation and analysis of data and information, to find out the relationship between quantity and quantity, aiming at the problem of reasonable assumptions will be transformed into a mathematical problem, establish mathematical model, using the computer to build the model, the final results of the analysis, test and evaluation. In order to solve the problem, finally completed a paper or report. Mathematical modeling for improving students' ability to use mathematics and computer technology to solve practical problems, the cultivation of innovation ability and practice ability, cultivate the spirit of unity and cooperation, improve the comprehensive ability of students has a very positive meaning.

In a word, the leading role of teachers should be put into practice, and the initiative of students' subjective learning can be put in place. The organic combination of the two will be more effective and faster to enhance students' mathematical thinking ability, and then develop a strong self-learning ability.

\section{References}

[1] X.X.Gu. Mathematics teaching in the cultivation of students' creative thinking of [J]. China occupation technology education, 2009, (26).(in Chinese)

[2] B.X.Yao, the new period of the relationship between teachers and students [J]. Educational development research, 2000, (10).(in Chinese)

[3] H.G.Zheng. The modern development of learning theory and its mathematical meaning [J]. 
Journal of mathematical education, 2004, (1).(in Chinese)

[4] R.L.Fan, and S.J.Wang. The connotation, process and teaching strategy of autonomous learning [J]. Tianjin Educational Science Press, 2007, (5).(in Chinese)

[5] L.J.Zhang. Pay attention to the training of mathematical thinking and develop good mathematical thinking mode [J]. Journal of Career Technical College, Anhui 7, (112-115.), 2008. (in Chinese) 